\title{
Caregiver-Related Intervention or Procedure
}

National Cancer Institute

\section{Source}

National Cancer Institute. Caregiver-Related Intervention or Procedure. NCI Thesaurus.

Code C116523.

Any intervention or procedure performed by a caregiver during the course of their duties. 